Human Ethology Bulletin 31 (2016)3: 5-14

Brief Report

\title{
AGE AND GENDER DIFFERENCES IN SMILING AND LAUGHTER: THE POWER ASYMMETRY HyPOTHESIS RETESTED
}

\author{
Lauren Poppy Robertson ${ }^{1}$ \& Yvan I. Russell ${ }^{1,2}$ \\ ${ }^{1}$ Department of Psychology, Middlesex University London, London, UK \\ ${ }^{2}$ CRC Evolution of Social Behaviour, University of Göttingen, Germany \\ yvanrussell@gmail.com
}

\begin{abstract}
The power asymmetry hypothesis puts smiling and laughter into the context of relationships, in particular the inequalities between people within interactions. As a means of appeasement, junior members are expected to display higher than usual rates of deliberately affiliative gestures towards senior (dominant) counterparts (compared to rates towards non-senior counterparts). Previous researchers found these effects for males but not females. In a new observational study, we compared rates of smiling and laughter within male-male and female-female dyads in bars and restaurants in London UK. Age was used as a proxy for social status (older presumed dominant). Individuals within these focal dyads were classified in two ways: sex, and estimated age (binary category using age thirty-five as a dividing line). Instances of smiling and laughter were classified as either deliberate or spontaneous. In total, 150 dyads were observed. Some power asymmetry effects were found for male-male but not female-female dyads. Younger males displayed higher rates of deliberate laughs towards older males and older males displayed more deliberate smiles towards other older males. Females displayed more affiliative behaviors when interacting with peers compared to older counterparts. These results partly replicate earlier studies and provide support for power symmetry effects amongst males only.
\end{abstract}

Key words: Smiling, laughter, power, gender, observation 


\section{INTRODUCTION}

The interaction between laughter, smiling, and social dominance has long been known, even appearing in an episode of Gogol's 1842 novel Dead Souls. The power asymmetry hypothesis was proposed by Preuschoft and van Hooff (1997) after they surveyed facial displays across non-human primate species. The non-human equivalent of smiling - the silent bared-teeth display - is observed among monkeys and apes as a gesture of appeasement, reassurance, or affiliation (or combination of these); and the non-human equivalent of laughter - the relaxed open-mouth display (with or without teeth showing) occurs only during social play (Preuschoft \& van Hooff, 1997). The extent of the appeasement function of smiling and laughing in a species will depend on the typical social dominance structure in that species (Preuschoft \& van Hooff, 1997): dominance comes into play where there are finite resources (e.g. food) that dominants can monopolize; appeasement allows a subordinate to access a resource (even if not receiving as much as the dominant). Among humans, smiling and laughter appear to have evolutionarily converged into overlapping functions (see reviews in Devereux \& Ginsburg, 2001, Gervais \& Wilson, 2005, Méhu \& Dunbar, 2008). The occurrence of laughter is influenced by social factors; it occurs more often when the laugher is in the presence of at least one other person (Devereux \& Ginsburg, 2001). Owren and Bachorowski (2003) have proposed that laughter functions to modulate the affective state of the perceiver of the laughter, which in term improves the perceiver's view of the laugher.

Social dominance is a ubiquitous feature of human life, leading to "coordinated differences in the behavioural repertoires of dominants and subordinates" (Pratto, Sidanius, \& Levin, 2006, p. 279). Accordingly, researchers have applied the power asymmetry hypothesis to humans (e.g. LaFrance \& Hecht, 1999). Méhu and Dunbar (2008) conducted an observational study of naturally occurring laughter and smiling among males in public settings (food courts and bars). Focal individuals in dyadic groups were classified according to sex and age category. Smiles were classified as being either deliberate or spontaneous. Their main results were that the power asymmetry hypothesis appeared to apply to males but not females. Specifically, they found particularly high rates of deliberate smiles directed by younger males towards older males (cf. Méhu, 2011). Ekman and Friesen (1982) identified two types of smiles relevant here: 'felt' (Duchenne smile) and 'false' smile, proposing that they each have different purposes (cf. Gervais \& Wilson, 2005). The felt smile translates to the spontaneous smile, in that it represents the expression of genuine joy. The false is representative of the deliberate smile in that it is "deliberately made to convince another person that a positive emotion is felt when it isn't" (Ekman \& Friesen, 1982, p. 244). Similarly, laughter can be either a Duchenne display (felt) or false (Ruch \& Ekman, 2001). Here, we emulate previous studies (LaFrance \& Hecht, 1999; Méhu \& Dunbar, 2008; Méhu, 2011) to explore power asymmetry effects across same-sex dyads. 


\section{METHOD}

Three were 150 dyads observed: 83 male-male $(\mathrm{m} / \mathrm{m}), 67$ female-female $(\mathrm{f} / \mathrm{f})$. Participants were unaware that they were part of a study (but an information sheet was prepared in case somebody noticed). Each dyad consisted of a focal individual (whose smiles and laughter are recorded) and the counterpart individual (gestures not recorded). To determine age category, the observer visually judged both focal and counterpart as being either being junior (appearing $\leq 35$ years) or senior (appearing 35+). Here, age is a proxy for social dominance/status, as used by Méhu and Dunbar (2008); which we justify (as they did) by the fact that personal incomes in the UK tend to increase after age 35 (HM Revenue \& Customs, 2016). Furthermore, age 35 is an age when life stability in acquired in various ways (Aviva Insurance Limited, 2012). In cases where it was difficult to categorize a person's age, a guess was made. Thus, there were 66 junior individuals $(33 \mathrm{~m}, 33 \mathrm{f})$ and 84 senior individuals ( 50 male, 34 female) for the focal individual. For the counterpart individual, there were 67 junior individuals ( 32 male, 35 female) and 83 senior individuals ( 51 male, 32 female) observed. Altogether, there were 39 junior-junior dyads observed $(17 \mathrm{~m} / \mathrm{m}, 22 \mathrm{f} / \mathrm{f})$, 56 senior-senior dyads $(35 \mathrm{~m} / \mathrm{m}, 21 \mathrm{f} / \mathrm{f}), 27$ dyads which were focal-junior counterpartsenior $(16 \mathrm{~m} / \mathrm{m}, 11 \mathrm{f} / \mathrm{f})$ and 28 dyads which were focal-senior and counterpart-junior $(15 \mathrm{~m} / \mathrm{m}, 13 \mathrm{f} / \mathrm{f})$. Little else was known about the participants. Anecdotally, it could be observed that the sample reflected the highly diverse cultures and lifestyles of London.

Naturalistic observations (between 12pm-12am) were conducted in eleven establishments (bars/restaurants) in central London UK. Signed consent was obtained from managers at each establishment. Participants were selected on the basis that they were engaging in conversation within a same-sex dyad, that the focal's face was fully visible, and that they were sitting within $2-10 \mathrm{~m}$ from the observer (up to $15 \mathrm{~m}$ if lighting allowed). Where the focal and counterpart could both be seen clearly, the counterpart may have later been observed as the focal. Selection of the focal in these cases was initially random and later based on a quota for underrepresented groups. Drawing on clear instructions from pertinent research literature (Ekman \& Friesen, 1975, 1982; Ruch \& Ekman, 2001), the sole observer (L.P.R.) trained herself beforehand to recognize spontaneous and deliberate smiles (prior to collecting data, she made a pilot study of 5-10 samples to train herself). Instantaneous focal sampling (Altmann, 1974) was used: a timer prompted recordings at one-minute intervals. The sample was discarded if the dyad was disbanded earlier than 15 minutes. If uninterrupted, observations were terminated after 25 minutes. Using a purpose-created checklist, observations of a focal dyad were coded as one of six categories: (1) spontaneous or (2) deliberate laughter, (3) spontaneous (Duchenne) or (4) deliberate smiles, (5) no laughing or smiling, or (6) invalid observation (e.g. face could not be seen). Table 1 illustrates the definitions drawn from the literature of both spontaneous (felt/Duchenne) and deliberate smiles and laughter. As for laughter, we handled it differently from Méhu and Dunbar (2008): whereas they coded laughter as a single category, we decided to differentiate spontaneous from deliberate laughter. As discussed by Ruch and Ekman 
(2001), spontaneous and deliberate laughs can be differentiated in the same way as those of smiles (see Table 1). This study was approved by the ethics committee at Middlesex University (Psychology).

Table 1: Definitions of spontaneous (felt) and deliberate (false) smile and laughter.

\begin{tabular}{|c|c|c|}
\hline Behaviour type & Felt & False \\
\hline $\begin{array}{l}\text { Smile } \\
\text { (Ekman \& Friesen, 1982) }\end{array}$ & 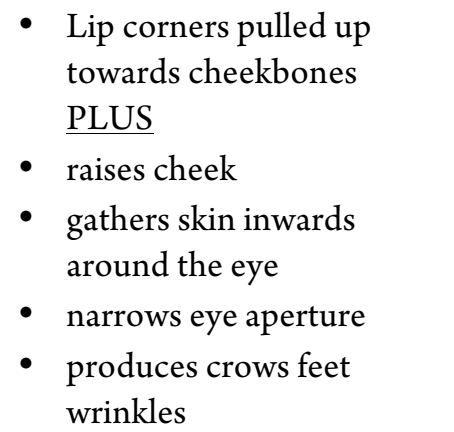 & $\begin{array}{l}\text { Lip corners pulled up } \\
\text { towards cheekbones } \\
\text { (note: extreme versions of the } \\
\text { above may influence muscles } \\
\text { used in felt smile, giving } \\
\text { appearance of felt smile) }\end{array}$ \\
\hline $\begin{array}{l}\text { Laugh } \\
\text { (Ruch \& Ekman, 2001) }\end{array}$ & $\begin{array}{l}\text { - Same as above } \\
\text { PLUS } \\
\text { - Relaxation of muscles } \\
\text { allowing lower of jaw } \\
\text { - Muscles widening the } \\
\text { mouth } \\
\text { - Possible narrowing of eyes } \\
\text { - Other muscles in body } \\
\text { involved with increasing } \\
\text { intensity }\end{array}$ & $\begin{array}{l}\text { - Same as above } \\
\text { PLUS } \\
\text { - Similar or same } \\
\text { movements as for felt }\end{array}$ \\
\hline
\end{tabular}

\section{RESULTS}

There were 150 dyads observed (mean duration 22.51 minutes, SD $=4.16$ ). Total observation time was 3376 minutes (56.27 hours), 39.2\% of which showed laughing/smiling. For each behaviour category, we calculated a rate by dividing the frequencies (collected instantaneously not continuously) by the number of valid observations in an observing session, creating a scale from $0-1$ (i.e. "invalid observations" were removed from the denominator). For total laugher/smiling (all four behaviours lumped together), there were a number of differences between males and females (see Table 2): we found that males displayed significantly more than females. When each type of smile and laugh was analyzed separately (see Figure 1 and Table 2), the significant difference remained for Duchenne smiles, deliberate smiles, and spontaneous laughs, but 
not for deliberate laughs. Regarding age, there was no significant difference overall between junior and senior subjects (male and female) for total laughter/smiling (senior mean = $0.492, \mathrm{SD}=0.314$; junior mean $=0.491, \mathrm{SD}=0.261$ ) $t(148)=-.029, \mathrm{p}=.977$ (nor for any of the separate categories).

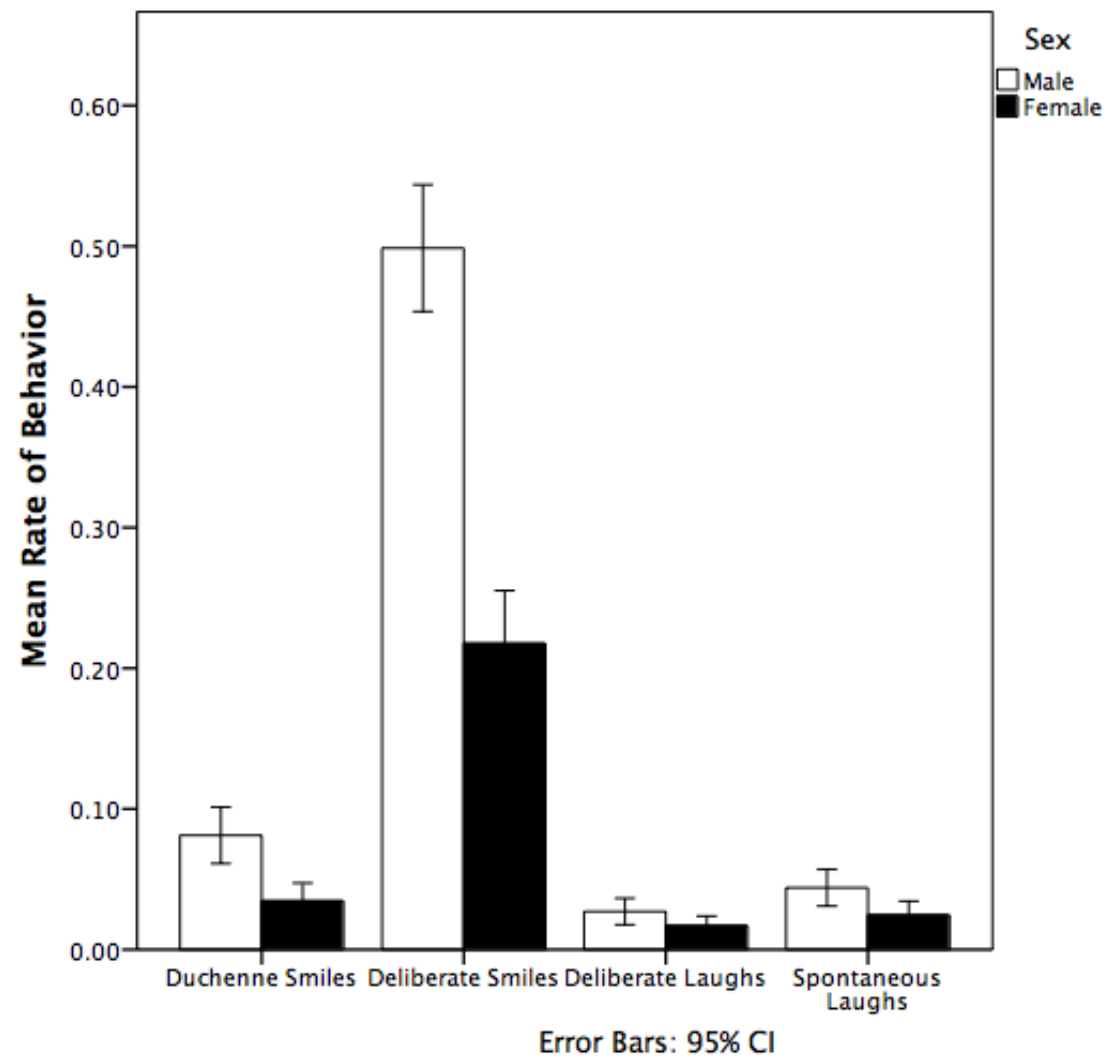

Figure 1: Overall rates of smiling and laughter per sex.

We also analyzed sex differences for all combinations of dyad (see Table 3). Starting with males, significant differences were found only for deliberate laughs and smiles. Neither senior nor juniors males showed significant differences towards senior versus junior counterparts in their rates of spontaneous smiling or laughter. For junior males, there was a significantly higher rate of deliberate laughs when the counterpart was a senior male compared to when the counterpart was another junior male - but there were no significant differences for other behaviours. For senior males, there was a significantly higher rate of deliberate smiles towards senior than towards junior counterparts - but there were no significant differences for other behaviours. For females, the pattern of results was quite different. Starting with junior females, there was a significantly higher rate of spontaneous laughs towards junior rather than senior females - but there were no significant differences for other behaviours. For senior females, there were no significant effects at all. 
Table 2: Sex differences in overall rates of laughter and smiling ( ${ }^{*}$ denotes significance at $\alpha=.05,{ }^{* *}$ denotes significance at $\alpha=.001)$.

\begin{tabular}{|c|c|c|c|c|c|c|}
\hline \multicolumn{2}{|c|}{ Behaviour category } & Sex & $\begin{array}{c}\text { Mean } \\
\text { (SD) }\end{array}$ & df & t-value & p-value \\
\hline \multicolumn{2}{|r|}{$\begin{array}{c}\text { Laughs } \\
+ \\
\text { Smiles }\end{array}$} & $\begin{array}{c}\text { Male } \\
\text { Female }\end{array}$ & $\begin{array}{c}0.651 \\
(0.244) \\
0.294 \\
(0.214) \\
\end{array}$ & 148 & 9.416 & $<.001^{* *}$ \\
\hline \multirow{2}{*}{ Laughs } & Spontaneous & $\begin{array}{c}\text { Male } \\
\text { Female }\end{array}$ & $\begin{array}{c}0.044 \\
(0.060) \\
0.025 \\
(0.041)\end{array}$ & 148 & 2.274 & $.024^{*}$ \\
\hline & Deliberate & $\begin{array}{c}\text { Male } \\
\text { Female }\end{array}$ & $\begin{array}{c}0.027 \\
(0.043) \\
0.017 \\
(0.028) \\
\end{array}$ & 148 & 1.659 & .099 \\
\hline \multirow{2}{*}{ Smiles } & Spontaneous & $\begin{array}{c}\text { Male } \\
\text { Female }\end{array}$ & $\begin{array}{c}0.081 \\
(0.092) \\
0.035 \\
(0.052) \\
\end{array}$ & 148 & 3.702 & $<.001^{* *}$ \\
\hline & Deliberate & $\begin{array}{c}\text { Male } \\
\text { Female }\end{array}$ & $\begin{array}{c}0.044 \\
(0.060) \\
0.025 \\
(0.041)\end{array}$ & 148 & 9.542 & $<.001^{* *}$ \\
\hline
\end{tabular}

\section{DISCUSSION}

Power asymmetry effects were found for males only, partially replicating previous work: only deliberate laughter was significant for juniors and only deliberate smiles were significant for seniors. Our social dominance measure is admittedly imprecise: we never knew the relationship history of an observed dyad, whether friend, family, or stranger, work colleague or not, romantically involved or not, etc. Thus, we cannot rule out the possibility that our results are muddied by misidentified dominance (e.g. older males who appeared socially dominant but weren't), or age miscategorization. Future studies might obviate these possible confounders by using more precise methods of measuring power asymmetry (e.g. acquiring more complete information, or creating a lab-based scenario). Our method also had some limitations: the instantaneous methods necessarily lost a lot of data (event occurring in between the minute markers were lost). Another limitation is that the measurement was binary: either a smile or laugh was recorded but not both. This loses out on some of the complexity of the social interaction whereupon smiles and laughter overlap. 
Table 3: Sex differences in smiling and laughter according to dyad composition $\left({ }^{*}\right.$ denotes significance at $\alpha=.05,{ }^{* *}$ denotes significance at $\left.\alpha=.001\right)$.

\begin{tabular}{|c|c|c|c|c|c|c|c|c|c|c|}
\hline \multicolumn{2}{|c|}{ Behavior category } & \multirow{2}{*}{ Dyad type } & \multicolumn{4}{|c|}{ Male-male dyad } & \multicolumn{4}{|c|}{ Female-female dayd } \\
\hline & & & Mean (SD) & df & t-value & p-value & Mean (SD) & df & t-value & p-value \\
\hline \multirow{8}{*}{ Laughs } & \multirow{4}{*}{ Spontaneous } & Junior to junior & $0.065(0.089)$ & \multirow{2}{*}{31} & \multirow{2}{*}{0.805} & \multirow{2}{*}{.427} & $0.049(0.047)$ & \multirow{2}{*}{31} & \multirow{2}{*}{3.425} & \multirow{2}{*}{$.003^{* *}$} \\
\hline & & Junior to senior & $0.045(0.054)$ & & & & $0(0)$ & & & \\
\hline & & Senior to senior & $0.036(0.040)$ & \multirow{2}{*}{48} & \multirow{2}{*}{0.123} & \multirow{2}{*}{.903} & $0.013(0.026)$ & \multirow{2}{*}{32} & \multirow{2}{*}{0.799} & \multirow{2}{*}{.430} \\
\hline & & Senior to junior & $0.038(0.064)$ & & & & $0.023(0.047)$ & & & \\
\hline & \multirow{4}{*}{ Deliberate } & Junior to junior & $0.016(0.039)$ & \multirow{2}{*}{31} & \multirow{2}{*}{-2.241} & \multirow{2}{*}{$.032^{*}$} & $0.017(0.032)$ & \multirow{2}{*}{31} & \multirow{2}{*}{0.664} & \multirow{2}{*}{.512} \\
\hline & & Junior to senior & $0.044(0.032)$ & & & & $0.010(0.024)$ & & & \\
\hline & & Senior to senior & $0.021(0.034)$ & \multirow{2}{*}{48} & \multirow{2}{*}{1.083} & \multirow{2}{*}{.284} & $0.013(0.026)$ & \multirow{2}{*}{32} & \multirow{2}{*}{-0.980} & \multirow{2}{*}{.335} \\
\hline & & Senior to junior & $0.037(0.068)$ & & & & $0.023(0.028)$ & & & \\
\hline \multirow{8}{*}{ Smiles } & \multirow{4}{*}{ Spontaneous } & Junior to junior & $0.081(0.087)$ & \multirow{2}{*}{31} & \multirow{2}{*}{0.972} & & $0.046(0.044)$ & & & \\
\hline & & Junior to senior & $0.054(0.072)$ & & & & $0.028(0.043)$ & & & \\
\hline & & Senior to senior & $0.563(0.139)$ & & & & $0.031(0.063)$ & & & \\
\hline & & Senior to junior & $0.363(0.253)$ & & & & $0.027(0.055)$ & 32 & -0.102 & 1 \\
\hline & & Junior to junior & $0.505(0.205)$ & & & & $0.281(0.115)$ & & & \\
\hline & Deliberate & Junior to senior & $0.479(0.236)$ & & & & $0.187(0.173)$ & & & \\
\hline & & Senior to senior & $0.563(0.137)$ & & & & $0.211(0.165)$ & & & \\
\hline & & Senior to junior & $0.363(0.025)$ & & & & $0.147(0.153)$ & & & \\
\hline
\end{tabular}


Sex differences were very distinct: males showed significantly higher overall rates than females in smiling (both spontaneous and deliberate) and deliberate laughter (contra LaFrance \& Hecht, 1999, who found that women smiled more, or Devereux \& Ginsburg, 2001, who found no sex differences). For spontaneous laughter, there was no significant difference between males and females; and spontaneous laughter happens to comprise the only age-related female result: junior females laughed spontaneously more with other juniors than with seniors - a nice result but not pertinent to power asymmetry effects. It might just be that power asymmetry effects in females are present but more difficult to detect (perhaps a larger or different sample is needed), but it is also plausible that females genuinely employ smiling and laughing differently (LaFrance \& Hecht, 1999). The appeasement function implied in studies of primatology (Preuschoft \& van Hooff, 1997) might be more of a male thing. One reason might be that female-style dominance is different from male-style dominance (de Waal, 1993). Another reason might be that smiling influences men more than women (Méhu, Little \& Dunbar, 2008). The pertinent variables in our own study (age, sex, relationship between interactants) should be brought into much sharper focus to enable us to explore this power asymmetry phenomenon further. This will clarify the functional importance and evolutionary background (Gervais \& Wilson, 2005; Owren \& Bachorowski, 2003; Preuschoft \& van Hooff, 1997) that makes smiling and laughter such an important feature of our daily lives.

\section{ACKNOWLEDGEMENTS}

We would like to thank two anonymous reviewers for their comments, the managers of the eleven establishments, the participants themselves, and Dr. Jackie Meredith from Middlesex University (module leader for B.Sc. dissertations).

\footnotetext{
1 "So it is with the faces of government clerks when the offices in their charge are being inspected by a newly arrived chief: when their first panic has passed off, and they see that he is pleased with a great deal and when he has graciously condescended to jest, that is to pronounce a few words with an agreeable simper, and the clerks standing near him laugh twice as much in response, those who have scarcely caught his words laugh with all their hearts too" (Gogol, 1842/1923, p. 228).
} 


\section{REFERENCES}

Altmann, J. (1974). Observational study of behavior: sampling methods. Behaviour, 49, 227-267. $\underline{\text { DOI }}$

Aviva Insurance Limited (2012). Times of Our Lives Report. Retrieved from: https://www.aviva.com/media/upload/FINAL-Times-of-our-Lives-October-2012.pdf

Devereux, P. G., \& Ginsburg, G. P. (2001). Sociality effects on the production of laughter. Journal of General Psychology, 128, 227-240. DOI

De Waal, F. B. M. (1993). Sex differences in chimpanzee (and human) behaviour: a matter of values? In M. Hechter, L. Nader, \& R. E. Michod (Eds.). The Origin of Values (pp. 285-303). New York: de Gruyter.

Ekman, P., \& Friesen,W. V. (1975). Unmasking the Face. Englewood Cliffs, NJ: Spectrum-Prentice Hall.

Ekman, P., \& Friesen,W. V. (1982). Felt, false and miserable smiles. Journal of Nonverbal Behavior, 6, 238-252. DOI

Gervais, M., \& Wilson, D. S. (2005). The evolution and functions of laugher and humour: a synthetic approach. Quarterly Review of Biology, 80, 395-430. DOI

Gogol, N. (1842/1923). Dead souls (C. Garnett, Trans.). New York: Modern Library / Random House.

HM Revenue \& Customs (2016). Distribution of median and mean income and tax by age range and gender. Retrieved from

https://www.gov.uk/government/uploads/system/uploads/attachment_data/file/503402/ Table_3_2_14.xlsx.

LaFrance, M., \& Hecht, M. A. (1999). Obliged to smile: the effect of power and gender on facial expression. In P. Philippot, R. S. Feldman, \& E. J. Coats (Eds.). The social context of nonverbal behavior (pp. 45-70). Cambridge: Cambridge University Press.

Méhu, M. (2011) Smiling and laughter in naturally occurring dyadic interactions; Relationship to conversation, body contacts, and displacement activities. Human Ethology Bulletin, 26, 10-28.

Méhu, M., \& Dunbar, R. I. M. (2008). Relationship between smiling and laughter in humans (Homo sapiens): testing the power asymmetry hypothesis. Folia Primatologica, 79, 269-280. DOI

Méhu, M., Little, A. C., \& Dunbar, R. I. M. (2007). Duchenne smiles and the perception of generosity and sociability in faces. Journal of Evolutionary Psychology, 5, 133-146. DOI

Owren, M. J., \& Bachorowski, J.-A. (2003). Reconsidering the evolution of nonlinguistic communication: the case of laughter. Journal of Nonverbal Behavior, 27, 183-200. DOI

Pratto, F., Sidanius, J., \& Levin, S. (2006). Social dominance theory and the dynamics of intergroup relations: taking stock and looking forward. European Review of Social Psychology, 17, 271-320. $\underline{\text { DOI }}$ 
Preuschoft, S., \& van Hooff, J. A. R. A. M. (1997). The social function of "smile" and "laughter": Variations across primate species and societies. In U. Segerstråle \& P. Molnár (Eds.). Nonverbal communication: where nature meets culture (pp. 171-189). Mahwah, NJ: Lawrence Erlbaum.

Ruch, W., \& Ekman, P. (2001). The expressive pattern of laughter. In A. W. Kaszniak (Ed.). Emotion, Qualia, and Consciousness (pp. 426-433). Tokyo: World Scientific. DOI 